\title{
Mid-trimester rupture uterus: case series
}

\author{
Aishwarya Kapur*, Sudha Prasad, Sangeeta Gupta
}

Department of Obstetrics and Gynecology, Maulana Azad Medical College and Associated Lok Nayak Hospital, Delhi, India

Received: 16 October 2017

Accepted: 17 November 2017

\section{*Correspondence:}

Dr. Aishwarya Kapur,

E-mail: aish9kapur@gmail.com

Copyright: (C) the author(s), publisher and licensee Medip Academy. This is an open-access article distributed under the terms of the Creative Commons Attribution Non-Commercial License, which permits unrestricted non-commercial use, distribution, and reproduction in any medium, provided the original work is properly cited.

\begin{abstract}
Uterine rupture is an obstetric catastrophe with significant maternal and fetal morbidity and mortality which occurs mainly in the third trimester of pregnancy or during labour, especially in previously scarred uterus. The occurrence of rupture in first and second trimester in women with unscarred uteri is quite rare. We report two cases of rupture uteri managed in our centre at 24 and 26 weeks gestation in women with unscarred uteri. First case was G3P1L1A1, 24 weeks with epigastric pain, stable vitals, epigastric tenderness, USG inconclusive, CT scan showed out pouching of amniotic sac through fundus. Laparotomy done, there was $8-9 \mathrm{~cm}$ fundal rupture extending between cornua, uterine repair done. Second case was G3P1L1A1 26 weeks with abdominal pain, stable vitals, corresponding fundal height, head engaged, USG revealed outpouching amniotic sac at the fundus. Laparotomy performed, there was $10 \mathrm{~cm}$ rent extending trans-fundal, uterine repair done. Unscarred uterine rupture, especially in early pregnancy is a rare event, posing significant difficulty in diagnosis. Uterine rupture should be first ruled out in all pregnant women presenting with acute abdomen irrespective of gestational age. Search for non-gynaecological causes can delay crucial obstetric intervention that can lead to loss of obstetric function, morbidity and mortality.
\end{abstract}

Keywords: Midtrimester rupture uterus, Non-gynaecological complaints in rupture uterus, Rupture uterus in early pregnancy, Unscarred uterine rupture

\section{INTRODUCTION}

Uterine rupture is an obstetric catastrophe with significant fetal as well as maternal morbidity and mortality which occurs mainly in the third trimester of pregnancy or during labour, especially in previously scarred uterus. The profile of causes and outcome varies between developing and developed countries. The incidence of uterine rupture among women with at least one prior CS is $0.2 \%$ to $1.0 \% 1$, adequate data is not available regarding the incidence in women with unscarred uterus. The occurrence of rupture in first and second trimester in women with unscarred uteri is quite rare. We report two cases of rupture uteri managed in our centre occurring at 24 and 26 weeks of gestation respectively, in women with unscarred uteri.

\section{CASE REPORT}

\section{Case 1}

31-year-old woman G3P1L1A1 with 24 weeks pregnancy was referred to us after being admitted in a peripheral center for two days with complaints of epigastric pain, where she was managed with antacids. Her first pregnancy was three years back, uneventful institutional full term normal vaginal delivery, followed by second pregnancy one year ago, in which dilation and curettage was done in view of incomplete abortion at two months amenorrhea. Present pregnancy was so far uneventful. She had complaints of abdominal pain for two days, with no other bladder/bowel complaints. She had no history of bleeding per vaginum. 
On arrival, her vitals were stable, PR 90/minute, BP $100 / 60 \mathrm{~mm}$ of $\mathrm{Hg}$, mild pallor, oxygen saturation $99 \%$, abdominal examination revealed epigastric tenderness and guarding, fundal height could not be made out clearly. Local examination had no bleeding, cervix was long and tubular. Investigations revealed hemoglobin 9 gm\%, other reports within normal limits, ultrasound was inconclusive with no free fluid and absent cardiac activity. CT scan showed out pouching of amniotic sac through the fundus with thinning of uterine wall (Figure $1)$.

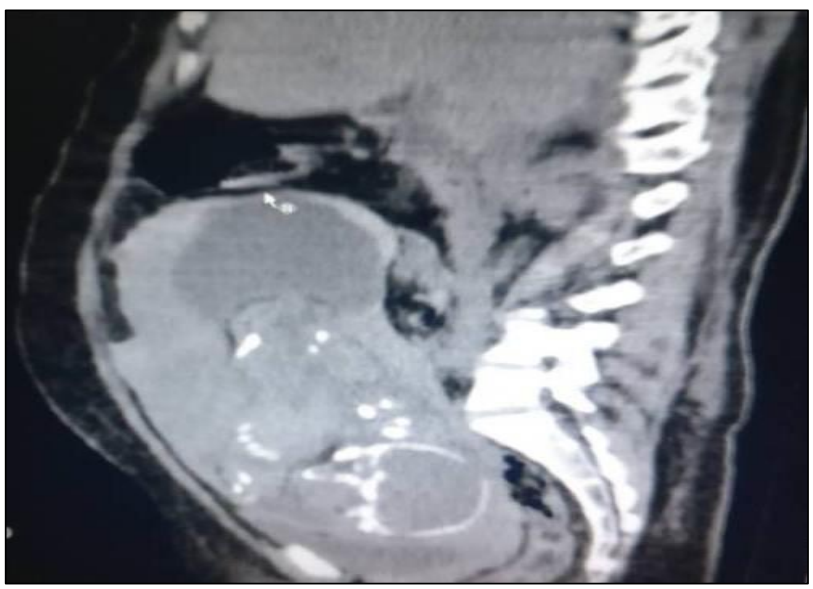

Figure 1: Computed Tomography image showing outpouching of amniotic sac through the fundus.

Immediate laparotomy was done, there was $500 \mathrm{cc}$ hemoperitoneum, 8-9 cm fundal rupture extending between cornua, intact amniotic sac protruding through it, fresh stillborn male fetus was delivered weighing 650 grams, placenta was fundal and anterior with no areas of morbid adherence (Figure 2 and 3). Uterine repair was done using vicryl number1, patient was discharged uneventfully with advice to avoid future conception.

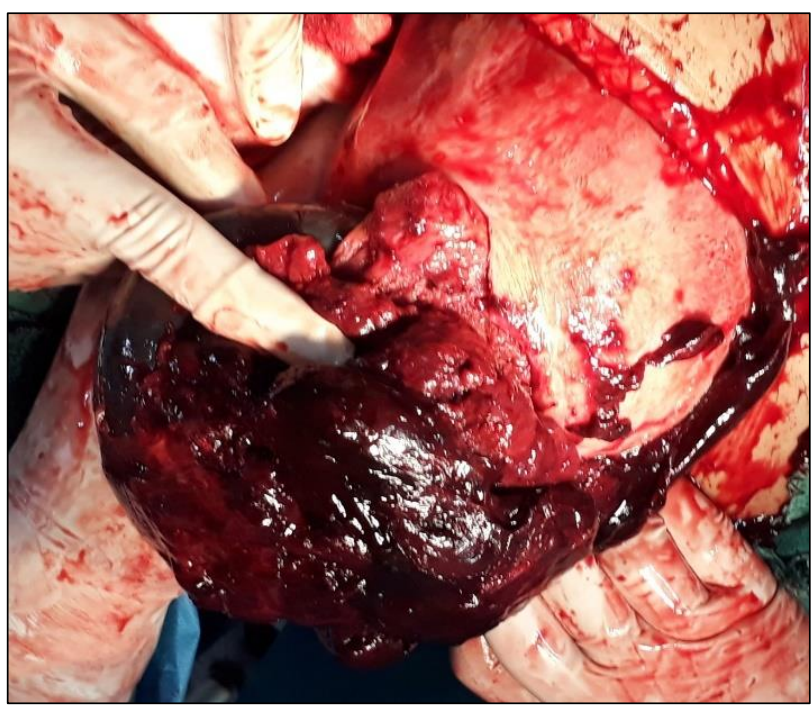

Figure 2: Intraoperative photograph showing intact amniotic sac protruding through uterine rent.

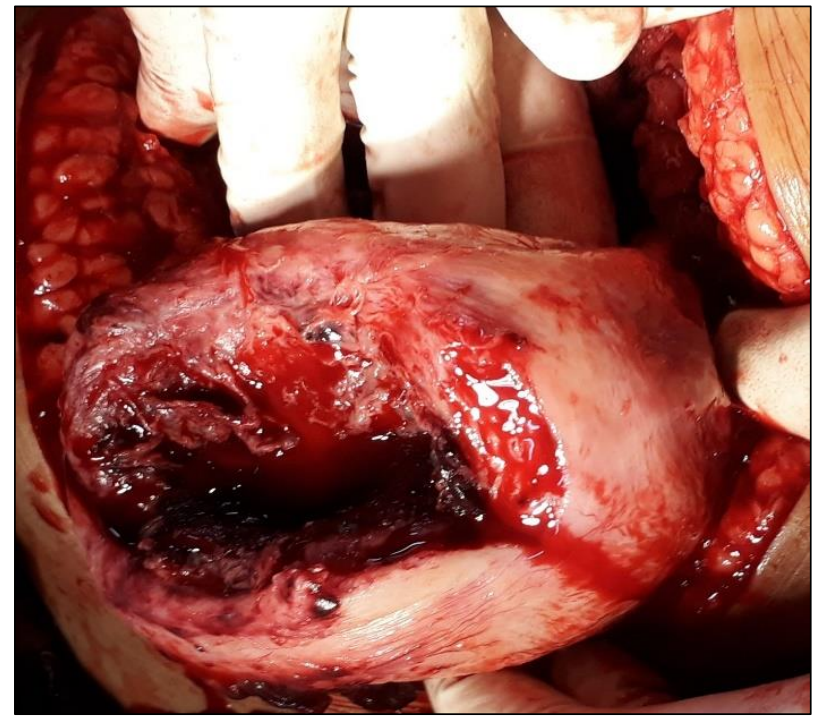

Figure 3: Intraoperative picture showing transfundal uterine rent.

Case 2

28-year-old woman G3P1L1A1 with 26 weeks period of gestation presented with abdominal pain for six hours, with no gastrointestinal or genitourinary complaints. Her first pregnancy was four years back, uneventful full term normal vaginal delivery at home, followed by second pregnancy two years ago, in which dilation and curettage was done in view of missed abortion at two months amenorrhea. She had gone to a peripheral centre where she was managed as a case of preterm labour and referred to tertiary centre for nursery facilities. On arrival, her PR was $100 /$ minute, BP $110 / 70 \mathrm{mmHg}$, pallor present, oxygen saturation $99 \%$. On abdominal examination, fundal height was 24 weeks, head engaged with nonlocalization of fetal heart sounds. There was tenderness and guarding in upper abdomen. Per vaginal examination had cervical dilation $2 \mathrm{~cm}$, partially effaced, intact membranes, vertex at -1 , no leaking/bleeding. Investigations showed hemoglobin $8.6 \mathrm{gm} \%$, other reports within normal limits, ultrasound revealed outpouching of amniotic sac at the fundus, absent fetal cardiac activity and mild free fluid in the abdomen. Immediate laparotomy was performed, there was $1000 \mathrm{cc}$ hemoperitoneum, $10 \mathrm{~cm}$ rent extending trans-fundal antero-posteriorly, intact amniotic sac with fetal parts protruding through the rent, fresh still born female fetus delivered weighing 720 grams, placenta was anterior, already separated. Uterine repair was done with vicryl number 1, two units of pack cell volume transfused intraoperatively. Patient was discharged in satisfactory condition with advice to avoid future pregnancy.

\section{DISCUSSION}

Uterine rupture is a life threatening obstetric emergency with a wide spectrum of risk factors and presentation causing significant diagnostic dilemmas. A retrospective 
study done in a tertiary care hospital in India reported the incidence of rupture uterus as one in 1,633 deliveries $(0.061 \%)$, with vast majority of patients having prior low transverse cesarean section $(84.8 \%))^{2}$ The major and easily identifiable risk factors are history of prior cesarean section, grand multiparity, obstructed labor, and fetal malpresentations and together they account for $90 \%$ of cases of uterine rupture.

Multiparity is a predisposing factor for all varieties of rupture, repeated pregnancies leading to increase in fibrous tissue and thinning of uterine musculature. Inappropriate and injudicious use of oxytocic drugs is a very common, and ideally preventable cause of uterine rupture. Prostaglandins are more potent and longer acting as compared to oxytocin and their use is associated with increased risk of tachysystole and hypertonus. ${ }^{3}$ These risk factors are applicable to cases of rupture occurring in third trimester, antepartum or intrapartum.

The classical history in a woman with rupture uterus is severe pain abdomen, vaginal bleeding and loss of fetal movements. As the hemoperitoneum increases, there may be features of peritonitis, hypovolemic shock and features of diaphragmatic irritation. Sudden cessation of labor pains and loss of station of presenting part are classical signs of rupture in a laboring woman. As such it is easier to suspect, diagnose and timely intervene in a woman with known risk factors presenting with these features.

Uterine rupture is a rare phenomenon in first and second trimesters and as such, there is no data in literature pertaining to incidence of such cases. Previous classical caesarean section, hysterotomy, myomectomy, metroplasty and cornual resection are obvious risk factors for uterine rupture. ${ }^{3}$ After reviewing cases reported in literature, various risk factors can be identified in women having early pregnancy rupture.

Uterine rupture has been reported at gestational age of 20 weeks following attempted midtrimester termination of pregnancy with prostaglandins in patient with previous low transverse caesarean section. ${ }^{4}$ Similar cases have been reported previously with the use of prostaglandins alone or in combination with oxytocin for midtrimester abortion.

Abdulwahab et al reported three cases of midtrimester rupture uterus. In one of them, they reported spontaneous rupture uterus at 15 weeks gestation in a woman with grand multiparity, one caesarean section and two dilation and curettage procedures done in previous pregnancies. ${ }^{5}$ The second case was rupture uterus identified at laparotomy done after failed induction (induction done at 24 weeks gestation for congenital anomaly in the fetus in a grand multipara with prostaglandins).

The third case was a grand multipara at 21 weeks gestation presenting with gastrointestinal symptoms.
Rupture uterus during early pregnancy has also been reported in cases with previous uterine scar and morbidly adherent placenta. The weakening of myometrium at the site of placental implantation in cases with morbid adherence results in rupture and resulting haemoperitoneum. ${ }^{6}$ Rupture uterus in women with adherent placenta has been reported by various authors at 14, 18, 21 weeks..$^{6-8}$ All these women had risk factors for placental adherence including previous hysterotomy and previous curettages.

Uterine anomalies are independent risk factors for uterine rupture, as well as morbid adherence of placenta. ${ }^{9-10}$ Haberal et al recently reported a case of spontaneous rupture uterus at 18 weeks of gestation in a woman with uterus didelphys and placenta percreta. ${ }^{9}$

The presentation of rupture uterus in early pregnancy is even more varied. In third trimester and during labour, imminent signs or rupture include continuous lower abdominal pain, fresh bleeding per vaginum, fetal heart rate decelerations, meconium stained liquor, cessation of uterine contractions, loss of station of presenting part and many other findings.

As discussed in above mentioned cases, the clinical presentation may be varied in patients having rupture uterus during first and second trimester. Vague nonspecific complaints may lead to suspicion of non gynaecological causes and eventually delay in diagnosis and appropriate management in these cases. In the two cases managed at our centre, there was no history of bleeding per vaginum.

The first patient primarily had gastrointestinal complaints of epigastric pain and occasional vomiting, which was attributed to normal physiological changes in pregnancy and was being managed with antacids. The absence of free fluid in ultrasound further complicated the diagnostic dilemma. However, no response to medical management, and thorough clinical assessment of surgeon ruling out any surgical cause, coupled with CT findings clinched the diagnosis and the patient was timely and successfully managed without significant morbidity. The second patient had even more confusing picture. Despite being in early labour with cervical dilation and mild pains, she had no vaginal bleeding and loss of station even after rupture uterus. However, the ultrasound clinched the diagnosis with outpouching of unruptured amniotic sac and mild free fluid in the abdomen.

Although history reviewed again retrospectively revealed uncomplicated single curettage in previous pregnancy in both the cases, still it can only be assumed that weakening of uterine fundus after perforation during curettage led to rupture during subsequent pregnancy. This emphasizes the importance of meticulous history taking in all patients. Further, perforations in gravid uterus during evacuations warrant exploration for 
completing evacuation and repairing the defect to prevent rupture in future pregnancies.

\section{CONCLUSION}

Unscarred uterine rupture, especially in early pregnancy is a rare and catastrophic event, posing significant difficulty in diagnosis. The importance of thorough medical history and detailed clinical examination cannot be underestimated. High index of suspicion in patients with history of interference in previous pregnancies should be help in making the diagnosis. Ultrasound findings of absent free fluid with an intrauterine pregnancy does not exclude rupture uterus. Uterine rupture should be first ruled out in all pregnant women presenting with acute abdominal pain irrespective of gestational age. Search for non-gynaecological causes in such clinical presentations can delay crucial obstetric surgical intervention that can lead to loss of obstetric function, morbidity and mortality.

Funding: No funding sources Conflict of interest: None declared

Ethical approval: Not required

\section{REFERENCES}

1. WHO. Incidence and outcomes of uterine rupture among women with prior caesarean section: WHO Multicountry Survey on Maternal and Newborn Health Sci Rep. 2017;7:44093.

2. Sinha M, Gupta R, Gupta P, Rani R, Kaur R, Singh R. Uterine rupture: a seven-year review at a tertiary care hospital in New Delhi, India. Indian J Community Med. 2016;41(1):45-9.

3. Baskett TF, Calder AA, Arulkumaran S. Uterine rupture. Munro Kerr's Operative Obstetrics. $11^{\text {th }}$ ed. Elsevier; 2007:175-80.
4. Pappalardo EM, Greca ML, Rapisarda G, Consoli D. Uterine rupture after prostaglandin analogues to induce midtrimester abortion. J Prenat Med. 2010;4(1):9-11

5. Abdulwahab DF, Ismail $H$, Nusee Z. Secondtrimester uterine rupture: lessons learnt. Malays J Med Sci. 2014;21(4):61-5.

6. Jang DG, Lee GSR, Yoon JH, Lee SJ. Placenta percreta-induced uterine rupture diagnosed by laparoscopy in the first trimester. Int $\mathrm{J}$ Med Sci. 2011;8(5):424-42.

7. Hornemann A, Bohlmann MK, Diedrich K, Kavallaris A, Kehl S, Kelling K, et al. Spontaneous uterine rupture at the $21^{\text {st }}$ week of gestation caused by placenta percreta. Arch Gynecol Obstet. 2011;284(4):875-8.

8. Wozniak S, Kłudka-Sternik M, Czuczwar P, Szkodziak P, Paszkowski M, Paszkowski T. Placenta percreta leading to uterine rupture at 18 weeks of pregnancy with consecutive hysterectomy: a case report. Ginekol Pol. 2013;84(4):318-20.

9. Haberal TE, Çekmez Y, Ulu İ, Divlek R, Göçmen A. Placenta percreta with concomitant uterine didelphys at 18 weeks of pregnancy: a case report and review of the literature. J Matern Fetal Neonatal Med. 2016;29(21):3445-8.

10. Martínez-Garza PA, Robles-Landa LP, Roca-Cabrera M, Visag-Castillo VJ, Reyes-Espejel L, GarcíaVivanco D. Spontaneous uterine rupture: report of two cases. Cir Cir. 2012;80(1):81-5.

Cite this article as: Kapur A, Prasad S, Gupta S. Mid-trimester rupture uterus: case series. Int J Reprod Contracept Obstet Gynecol 2018;7:342-5. 